\title{
ВАРЬИРОВАНИЕ СОДЕРЖАНИЯ КОЛИЧЕСТВА КЛЕЙКОВИНЫ В ЗЕРНЕ МЯГКОЙ ЯРОВОЙ ПШЕНИЦЫ ПОД ВЛИЯНИЕМ МЕТЕОРОЛОГИЧЕСКИХ УСЛОВИЙ КРАСНОЯРСКОГО КРАЯ
}

V.V. Keler

\section{GLUTEN CONTENT VARIATION IN SOFT SPRING WHEAT GRAIN UNDER THE INFLUENCE OF METEOROLOGICAL CONDITIONS IN KRASNOYARSK REGION}

Келер Виктория Викторовна - канд. с.-х. наук, доц. каф. растениеводства, селекции и семеноводства Красноярского государственного аграрного университета, г. Красноярск.

E-mail: vica_kel@mail.ru

Цель работы - оценка роли температурного фрактора и условий влагообеспечения в течение вегетационного периода в фоормировании количества клейковины яровой мягкой пшеницы в условиях южной лесостепи Красноярского края. Задачи: оценить сорта мягкой яровой пшеницы в южной лесостепи Красноярского края по содержанию клейковины и установить маситабы изменчивости признака, выявить роль температурного фактора в формировании анализируемого показателя у исследуемой культуры и рассмотреть влияние содержания влаги в течение вегетационного периода и ее вклад в изменение количества клейковины у мягкой яровой пшеницы. Для выполнения поставленных на исследование задач в 2007-2017 г2. бьл заложен опыт по методике конкурсного испытания на Каратузском ГСУ. Повторность в эксперименте 4-кратная, площадь делянки - 25 м². Изучались сорта Новосибирская 15, Ветлужанка, Омская 33 и Кантегирская 89. Результаты были обработаны методом математической статистики с помощью пакета StatSofte STATISTICA 6.0. Установлено, что варьирование содержания клейковины у изученных образиов за анализируемый период было низким и показатель стабилен (при V om 1,8 до 4,5 \%). Содержание клейковины увеличивается под воздействием повышенных температур и осадков июля, $r$ изменяются от 0,355 у сорта Новосибирская 15 до 0,645 у Омская 33. Отрицательным действием на увеличение клейковины отличаются осадки августа, изменчивость коэффрициентов корреляции со-
Keler Victoria Victorovna - Cand. Agr. Sci., Assoc., Chair of Plant Growing, Selection and Seed Farming, Krasnoyarsk State Agrarian University, Krasnoyarsk.

E-mail: vica_kel@mail.ru

ставила от -0,109 у сорта Новосибирская 15 до -0,533 у сорта Ветлужанка.

Ключевые слова: яровая пшеница, температура, осадки, влагообеспеченность, клейковина, вегетация, сорт, корреляция, зерновые, азот, зерно, метеорология, хлебопечение.

The aim of the study was to evaluate the role of temperature factor and moisture conditions during vegetative season in the formation of gluten amount in soft spring wheat in Krasnoyarsk Region. The tasks were to evaluate soft spring wheat varieties cultivated in Krasnoyarsk Region in terms of gluten content and to establish the scope in trait variability; to identify the temperature factor role in the formation of analyzed indicator in studied culture; to consider the influence of moisture supply during vegetative season and its contribution to gluten content variation in soft spring wheat. To fulfill the tasks in 2007-2017 the experiment was laid by the method of competitive testing at the Karatuz State Plot Studying Varieties. The frequency of the experiment was 4-fold, the area of the allotment made 25 sq.m. The varieties Novosibirskaya 15, Vetluzhanka, Omskaya 33 and Kantegirskaya 89 were investigated. The results were processed using mathematical statistics the StatSoft ${ }^{\circledR}$ STATISTICA 6.0 package. It was established that studied samples for analyzed period had had a low variation of gluten content and the indicator had been stable (at $V$ from 1.8 to $4.5 \%$ ). The content of gluten increased under the influence of high temperatures and rainfall of July, $r$ changed from 0.355 in the variety Novosibirskaya 15 to 0.645 in Omskaya 33. The 
precipitation in August had a negative effect on it, the variability of the correlation coefficients ranged from 0.109 in Novosibirskaya 15 variety up to -0.533 in Vetluzhanka.

Keywords: spring wheat, temperature, precipitation, moisture content, gluten, vegetation, variety, correlation, cereals, nitrogen, grain, meteorology, bread-baking.

Введение. Яровая мягкая пшеница является основной продовольственной культурой в Красноярском крае. Полученное зерно используется для нужд хлебопечения. В современных условиях роль технологических качеств получаемого зерна особенно важна. В связи с переходом на самообеспечение высококачественным зерном районов Восточной Сибири перед селекционерами стоит задача создания сортов мягкой яровой пшеницы местной селекции, характеризующихся высокими мукомольными и хлебопекарными качествами [1].

На формирование урожая яровой пшеницы и его качество в лесостепи Красноярского края оказывает влияние сложный комплекс погодных условий. Обработка многолетних данных по содержанию клейковины позволит выявить характер ее изменчивости под влиянием условий внешней среды, определить устойчивость признака и определить пути совершенствования вновь выводимых сортов.

Цель работы. Оценка роли температурного фактора и условий влагообеспечения в течение вегетационного периода в формировании количества клейковины яровой мягкой пшеницы в условиях южной лесостепи Красноярского края.

Задачи: оценить сорта мягкой яровой пшеницы в южной лесостепи Красноярского края по содержанию клейковины и установить масштабы изменчивости признака; выявить роль температурного фактора в формировании анализируемого показателя у исследуемой культуры; рассмотреть влияние содержания влаги в течение вегетационного периода и ее вклад в изменение количества клейковины у мягкой яровой пшеницы.

Объекты и методы исследования. Для выполнения поставленных задач по оценке сортов мягкой яровой пшеницы, выращиваемых на территории лесостепи Красноярского края, по содержанию клейковины и выявления роли метеорологических условий в формировании анализи- руемого показателя в 2007-2017 гг. был заложен опыт по методике конкурсного испытания на Каратузском ГСУ [2]. Почвенный покров представлен черноземом обыкновенным. Повторность в эксперименте 4-кратная, площадь делянки $25 \mathrm{~m}^{2}$ [3]. В настоящей работе изучены сорта Новосибирская 15, Ветлужанка, Омская 33 и Кантегирская 89. Содержание клейковины определяли по методике ГОСТ 27839-2013 [4]. В результате проведенных исследований материалы конкурсного сортоиспытания были обработаны методом математической статистики с помощью пакета StatSoft@ STATISTICA 6.0 [5].

Результаты исследования и их обсуждение. Хорошо известно, что содержание клейковины в пшенице и физические свойства, характеризующие ее качество, могут варьировать очень широко. Содержание клейковины обычно хорошо коррелирует с количеством белка в зерне, что вполне объяснимо, поскольку клейковина в основном является белковым веществом. Исключение составляют те случаи, когда под влиянием определенных воздействий клейковины белок резко меняет свои физико-химические свойства и поэтому лишается в большей или меньшей степени способности образовывать слитую гидратированную массу сырой клейковины, что приводит к снижению выхода отмытой клейковины при достаточном содержании общего белка в зерне. Примером может служить пшеница, поврежденная жуком-клопом, ранними заморозками, проросшая на корню или испорченная неправильными методами обработки и хранения (пересушенное, самонагревающееся зерно и др.).

Для пшеницы с клейковиной хорошего и среднего качества содержание последней в зерне определяется теми же факторами, что и содержание общего белка. Сортовые характеристики пшеницы, метеорологические условия вегетации и особенности периода созревания, сельскохозяйственные мероприятия (подготовка почвы, севооборот, внесение удобрений, орошение и др.) - все это влияет на содержание клейковины в том же направлении, что и содержание белка в зерне.

Самым высоким содержанием клейковины при оценке ее среднего значения за 10 лет отличался сорт Новосибирский 15 - 33,7 \%. Диапазон варьирования признака в этой выборке был низким: от 31,9 до 34,5 \% при вариации 
всего в 2 \% (табл. 1). После этого сорта второе место занимают Ветлужанка и Кантегирская 89 с содержанием клейковины 32,6 \%. На последнем месте среди анализируемых образцов находится сорт Омская 33, среднее содержание клейковины за исследуемый период составило $31 \%$, размах изменчивости признака свидетельствует, что в 2009 году содержание клейковины в ее зерне составляло $28,4 \%$.

Таблица 1

Изменчивость содержания клейковины у сортов яровой мягкой пшеницы (2007-2017 гг.), \%

\begin{tabular}{|l|c|c|c|}
\hline \multicolumn{1}{|c|}{ Сорт } & $\lim$ & $\mathrm{M} \pm \mathrm{m}$ & $\mathrm{V}, \%$ \\
\hline Ветлужанка & $31,8-33,3$ & $32,6 \pm 1,1$ & 1,8 \\
\hline Омская 33 & $28,4-33,5$ & $31,3 \pm 1,3$ & 4,5 \\
\hline Кантегирская 89 & $30,9-33,4$ & $32,6 \pm 1,0$ & 2,4 \\
\hline Новосибирская 15 & $31,9-34,5$ & $33,7 \pm 0,9$ & 2,4 \\
\hline
\end{tabular}

По требованиям к содержанию клейковины в высококлассном зерне пшеницы ее должно быть не менее $28 \%$. По нашим данным, все сорта за исследуемый период формировали зерно с качеством, соответствующим этому па- раметру (рис.). Варьирование показателя низкое - от 1,8 до 4,5 \%, что указывает на стабильность признака у изучаемых сортов в данной зоне.

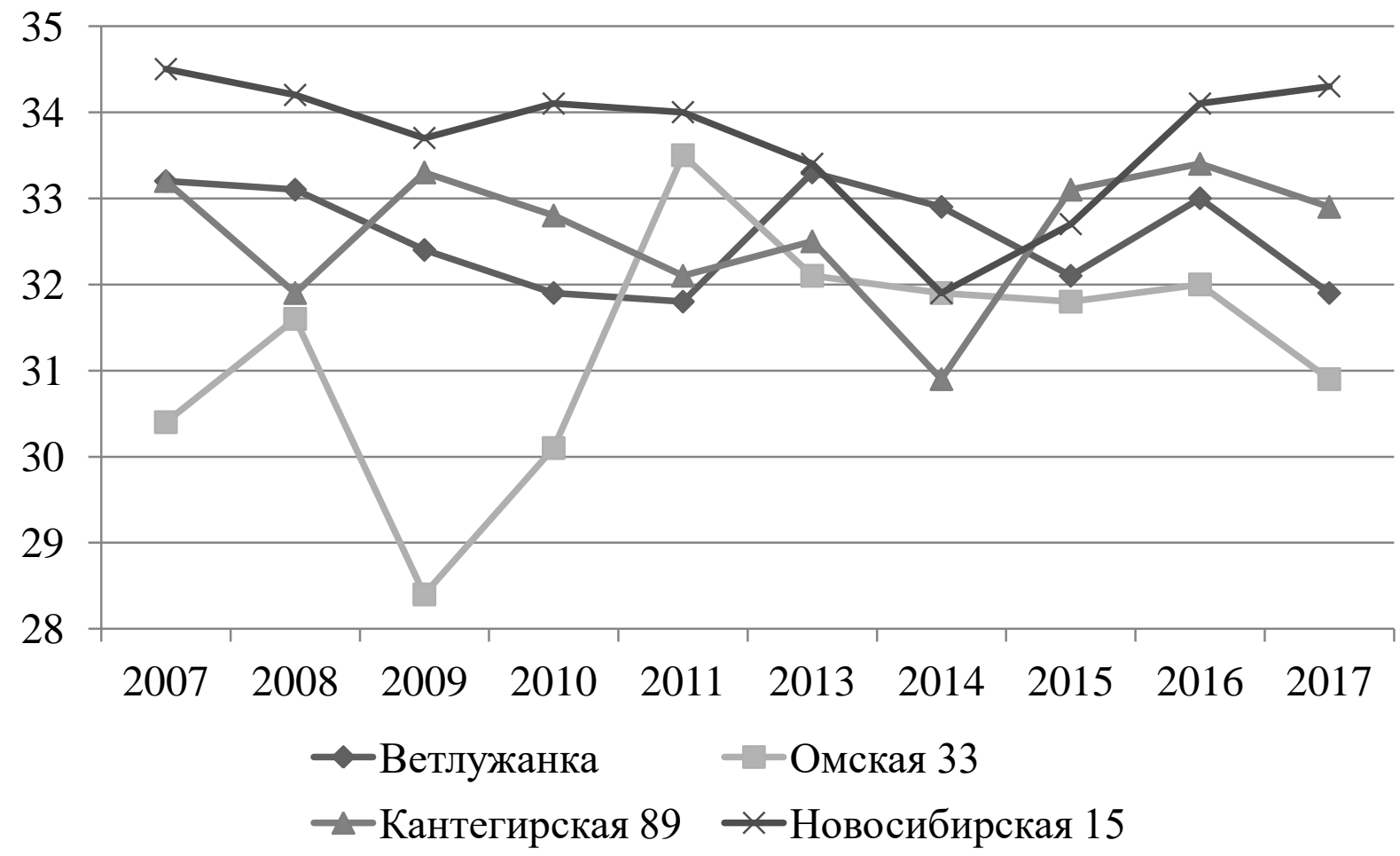

Содержание клейковины в зерне мягкой яровой пшеницы в Каратузском ГСУ (2007-2017 г2.), \% 
Роль температурного фактора в формировании содержания клейковины в зерне яровой пшеницы в условиях Каратузского ГСУ, 2007-2017 гг.*

\begin{tabular}{|l|c|c|c|c|c|}
\hline \multirow{2}{*}{\multicolumn{1}{c|}{ Сорт }} & \multicolumn{5}{|c|}{ Месяц } \\
\cline { 2 - 6 } & Май & Июнь & Июль & Август & Сентябрь \\
\hline Ветлужанка & 0,111 & $-0,229$ & 0,564 & 0,045 & $-0,243$ \\
\hline Омская 33 & $-0,154$ & $-0,184$ & 0,645 & 0,047 & $-0,083$ \\
\hline Новосибирская 15 & $-0,058$ & 0,458 & 0,395 & 0,269 & $-0,333$ \\
\hline Кантегирская 89 & $-0,211$ & $-0,199$ & 0,410 & 0,167 & $-0,351$ \\
\hline
\end{tabular}

${ }^{*} \mathrm{~m}^{\mathrm{r}} 0,245-0,255$.

Судя по данным таблицы 2, среднемесячные температуры мая и июня на величину клейковины у изучаемых сортов яровой пшеницы в зоне южной лесостепи существенного влияния не оказывали. В единственном случае на увеличение теплообеспеченности в июне откликался сорт Новосибирская 15 (коэффрициент корреляции составил 0,458), то есть с увеличением температуры этого периода содержание клейковины у него повышается, возможно, такой характер связей можно объяснить тем, что сорт ранний, и в конце июня у него идет формирование органов цветка и соцветия, а повышение теплообеспеченоости в это время положительно сказывается на этих процессах.

Наиболее существенная корреляция содержания клейковины в зерне с увеличением температур проявились в связях с июлем. Все сор- та положительно реагируют на повышение тепла во второй летний месяц, о чем свидетельствуют коэффициенты корреляции ( $r$ менялся от 0,395 у сорта Новосибирская 15 до 0,645 у сорта Омская 33). Это объясняется тем, что в данный период идет завершение процессов формирования всех органов соцветия, опыление и оплодотворение, формирование зерновки, которые имеют положительную зависимость от достаточной теплообеспеченности. В августе и сентябре характер этих связей ослабевает и коэффициенты корреляции снижаются.

Рассмотрев характер и силу связей содержания клейковины с влагообеспеченностью периода вегетации, мы установили, что самое существенное действие на исследуемый признак качества у яровой пшеницы изучаемых сортов оказывают осадки, выпавшие в июле и августе (табл. 3).

Таблица 3

\section{Роль влагообеспеченности в формировании клейковины в зерне яровой пшеницы в условиях Каратузского ГСУ, 2007-2017 гг. *}

\begin{tabular}{|l|c|c|c|c|c|}
\hline \multirow{2}{*}{\multicolumn{1}{c|}{ Сорт }} & \multicolumn{5}{|c|}{ Месяц } \\
\cline { 2 - 6 } & Май & Июнь & Июль & Август & Сентябрь \\
\hline Ветлужанка & $-0,230$ & $-0,078$ & 0,425 & $-0,533$ & $-0,230$ \\
\hline Омская 33 & $-0,155$ & 0,017 & 0,359 & $-0,626$ & $-0,079$ \\
\hline Новосибирская 15 & $-0,240$ & $-0,217$ & 0,374 & $-0,355$ & $-0,296$ \\
\hline Кантегирская 89 & $-0,013$ & 0,179 & $0,392-$ & $-0,381$ & $-0,217$ \\
\hline
\end{tabular}

${ }^{*} \mathrm{~m}^{\mathrm{r}} 0,095-0,250$.

Июльские осадки обладают положительным действием на формирование количества клейковинных комплексов. Самым отзывчивым оказался сорт Ветлужанка - коэфффициент корреляции у него достигал 0,425 , далее располагается сорт Кантегирская 89 с коэффрициентом корреляции 0,392. Осадки, выпавшие в этот пе- риод, положительно сказывались на выходе в трубку и цветении яровой пшеницы, а также и на дальнейшем развитии растений, то есть повышение влагобеспеченности в критический период у данной культуры оказывает благоприятное воздействие и на качество зерна. 
В августе картина становится противоположной, избыточное увлажнение в этот период приводит к снижению содержания клейковины, полученные отрицательные связи можно объяснить вымыванием микро- и макроэлементов, ухудшением газового режима почвы, ослаблением микробиологической активности. Растения могут подвергаться действию корневых и листовых гнилей [6]. Все эти фракторы негативно влияют на показатель содержания клейковины в зерне мягкой яровой пшеницы изученных районированных сортов.

Влагообеспеченность мая, июня и сентября существенного влияния на содержание клейковины в зерне у изученных сортов не оказывала.

\section{Выводы}

1. Среднее содержание клейковины у изученных сортов мягкой яровой пшеницы в зоне южной лесостепи Красноярского края за годы исследований составило от 31,3 до 33,7 \% при варьировании от 1,8 до 4,5\%. Максимальное количество клейковины в данной зоне формирует сорт Новосибирская $15-33,7 \%$.

2. Содержание клейковины увеличивается под воздействием повышенных температур и осадков июля, $r$ изменяются от 0,355 у сорта Новосибирская 15 до 0,645 у Омской 33. Отрицательным действием на количество клейковины характеризуются осадки августа, изменчивость коэфффициентов корреляции составила от $-0,109$ у сорта Новосибирская 15 до $-0,533$ у сорта Ветлужанка.

\section{Литература}

1. Келер В.В. Экологические и сортовые особенности формирования технологических качеств яровой пшеницы в лесостепи Красноярского края / Краснояр. гос. аграр. ун-т. - Красноярск, 2007. - 123 с.

2. Методика государственного сортоиспытания сельскохозяйственных культур (общая часть). Вып. 1. - М.: Колос, 1985. - 269 с.
3. Методика государственного сортоиспытания сельскохозяйственных культур. Вып. 2. Зерновые, крупяные, зернобобовые, кукуруза и кормовые культуры / ред. А.И. Григорьева. - М.: Колос, 1989. - 194 с.

4. ГОСТ 27839-2013. Мука пшеничная. Методы определения количества и качества клейковины: нац. стандарт Рос. Федерации. - М.: Стандартинформм, 2014. - 128 с.

5. Хижняк С.В., Пучкова Е.П. Математические методы в агроэкологии и биологии: учеб. пособие / Краснояр. гос. аграр. ун-т. - Красноярск, 2019. - 244 с.

6. Келер В.В. Роль экологических условий в формировании урожайности ярового ячменя в Канской лесостепи // Вестник КрасГАУ. - 2013. - № 7. - C. 86-88.

\section{Literatura}

1. Keler V.V. Ekologicheskie i sortovye osobennosti formirovaniya tekhnologicheskih kachestv yarovoj pshenicy $v$ lesostepi Krasnoyarskogo kraya / Krasnoyar. gos. agrar. un-t. - Krasnoyarsk, 2007. - $123 \mathrm{~s}$.

2. Metodika gosudarstvennogo sortoispytaniya sel'skohozyajstvennyh kul'tur (obshchaya chast'). Vyp. 1. - M.: Kolos, 1985. - 269 s.

3. Metodika gosudarstvennogo sortoispytaniya sel'skohozyajstvennyh kul'tur. Vyp. 2. Zernovye, krupyanye, zernobobovye, kukuruza i kormovye kul'tury / red. A.l. Grigor'eva. - M.: Kolos, 1989. - 194 s.

4. GOST 27839-2013. Muka pshenichnaya. Metody opredeleniya kolichestva i kachestva klejkoviny: nac. standart Ros. Federacii. - M.: Standartinform, 2014. - $128 \mathrm{~s}$.

5. Hizhnyak S.V., Puchkova E.P. Matematicheskie metody $\mathrm{V}$ agroekologii $\mathrm{i}$ biologii: ucheb. posobie / Krasnoyar. gos. agrar. un-t. - Krasnoyarsk, 2019. - $244 \mathrm{~s}$.

6. Keler V.V. Rol' ekologicheskih uslovij v formirovanii urozhajnosti yarovogo yachmenya v Kanskoj lesostepi // Vestnik KrasGAU. 2013. - № 7. - S. 86-88. 